\title{
Water taste in man
}

LIROA M. BARTOSHUK

PIONEERING RESEARCH LABORATORY, U. S. ARMY NATICK LABORATORIES, NATICK, MASSACHUSETTS

Taste quality and intensity shifts following adaptation to $\mathrm{NaCl}$, quinine hydrochloride, sucrose and $\mathrm{HCl}$ were investigated in $10 \mathrm{Ss}$. In each of four sessions, Ss were adapted to water and two concentrations of one taste solution and gave magnitude estimates and quality judgments for a series of concentrations of that solution. Adapting to water produced magnitude estimates which increased with increasing concentration. Quality judgments were typical, e.g., "salty" for $\mathrm{NaCl}$. Adapting to moderate concentrations of taste solutions generally produced magnitude estimates of zero at the adapting concentrations and increasing values for higher and lower (sub-adapting) concentrations. Sub-adapting tastes were atypical. Adaptation to $\mathrm{NaCl}$ and sucrose produced bitter sub-adapting tastes and adaptation to $\mathrm{HCl}$ and quinine hydrochloride produced sweet sub-adapting tastes. Water, as the lowest sub-adapting "concentration", produced the largest sub-adapting tastes.

A number of different opinions have been offered concerning the taste of distilled water in man. Some investigators have stated that water is tasteless (Kahlenberg, 1898; Richards, 1898). Electrophysiological recordings in man showing only decrements in neural activity with water on the tongue have been used to strengthen this point of view (Zotterman \& Diamant, 1959). However, a number of investigators have reported subjects that call water bitter (Camerer, 1870; Klesow, 1894; Luciani, 1917; Brown, 1914; Parker, 1922; Anderson, 1959). A third group of investigators reported distilled water to be insipid or flat. Haller (1751) and Henle (1880) considered the insipid taste to result from any solution with less salt than saliva. However, Öhrwall (1891) suggested that the insipid taste resulted from expecting the sensations produced by the carbonic acid usually present in fresh drinking water when they did not occur. In addition to observations about the taste of water per se, some anecdotal observations were made in the last century about the tastes water could take on when the tongue had previously been exposed to some other solution. Nagel (1896), for example, noted that water tasted sweet after gargling potassium chlorate. Several other such observations were accumulated indicating that water tasted sweet after some other salts and some acids (Von Skramlik, 1926). However, these effects were considered to be unusual and were never associated with the controversy over whether water was inherently bitter, tasteless or insipid. Bartoshuk et al (1964) attempted to resolve this controvery by showing that the "inherent" taste of water as bitter or tasteless was related to the prior solution on the tongue, just as the water tastes observed in the last century were. When the saliva, which usually covers the tongue, was removed by rinsing with distilled water, subsequent water stimuli were tasteless. When the tongue was adapted to $\mathrm{NaCl}$ solutions, however, water as well as those $\mathrm{NaCl}$ concentrations below the adapting concentration were called bitter or sour on some trials and tasteless on others. As the concentration of the adapting solution was increased, more judgments of bitter or sour resulted and in addition, the intensity of the bitter and sour tastes increased (McBurney, 1966). Thus normal salivary sodium variations could account for the controversy over whether water is tasteless or bitter. The insipid taste ascribed by some to water was not reported. The term "insipid" may have referred to a near-threshold bitter or sour taste.

\section{Subjects}

\section{METHOD}

Ten graduate students in psychology were used as Ss. They were not informed of the purpose of this study but were familiar with psychophysical methods. Each $S$ served in four sessions, one for each of the taste stimuli used.

\section{Apparatus}

All solutions were kept in a water bath at $34^{\circ} \mathrm{C}$ and were delivered to the tongue by a gravity flow system similar to that described by McBurney (1966). Adapting solutions and test solutions were delivered into the flow system through separate funnels in the water bath but emptied into the same glass tubing near the tongue. A stopcock at the junction of the funnels was used to switch from the adapting solution to the test solution. The test solution forced the adapting solution remaining in the delivery tube onto the tongue for approximately 2 sec after switching, so there were no cues for the exact onset of the test stimulus except a change from the adapting solution to the test stimulus.

\section{Solutions}

The four different taste stimuli used were $\mathrm{NaCl}$, quinine hydrochloride (QHCl), sucrose and $\mathrm{HCl}$. All solutions were made with distilled water and reagent grade chemicals except for sucrose solutions which were made with commercial grade sucrose. In each session three different adapting solutions were used; water and two concentrations of the taste stimulus for that session. The test stimulus concentrations were chosen so that some would be more concentrated than the adapting solution (supra-adapting) and some less concentrated (sub-adapting) for each of the two non-water adapting solutions. 


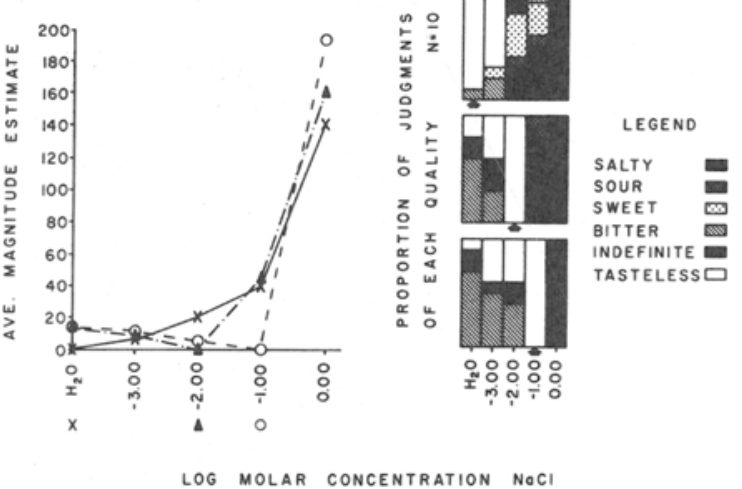

Fig. 1. Effects of adaptation to $\mathrm{NaCl}$ on quality judgments and magnitude estimates of a concentration series of $\mathrm{NaCl}$ solutions $(\mathbf{N}=\mathbf{1 0})$.

\section{Presenfation of Stimuli}

Each trial consisted of $40 \mathrm{sec}$ of adapting solution followed by the test solution both flowing at the rate of $4 \mathrm{ml} / \mathrm{sec}$. Ss were instructed to report both the magnitude and quality of the test stimulus. A magnitude standard of $0.3 \mathrm{M} \mathrm{NaCl}$ following adaptation to distilled water was provided and arbitrarily given a magnitude of 100 . Ss wrote magnitude estimates on response sheets under columns headed "tasteless," "salty," "sweet," "sour," or "bitter." An additional column was provided for tastes not described by one of the headings. Ss were instructed to note cases in which the adapting taste did not disappear and also to note whether the test stimulus following was the same taste and magnitude as the adapting solution. Generally, adaptation was complete in $40 \mathrm{sec}$ for all taste solutions and concentrations used. However, a few Ss reported that the sour taste of the $\mathrm{HCl}$ adapting solutions did not disappear. Thus when the test stimulus was the same concentration as the adapting stim-

MAGNITUDE ESTIMATES

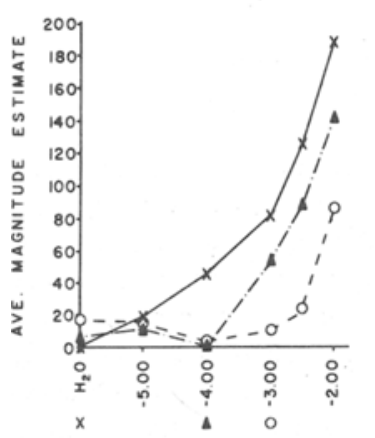

LOG MOLAR CONCENTRATION QHCI

Fig. 2. Effects of adaptation of QHCl on quality judgments and magnitude estimates of a concentration series of QHCl solutions $(\mathbf{N}=\mathbf{1 0})$.

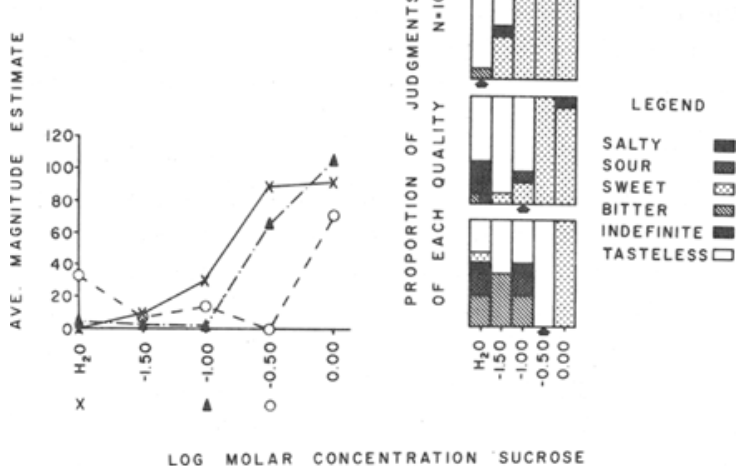

Fig. 3. Effects of adaptation to sucrose on quality judgments and magnitude estimates of a concentration series of sucrose solutions $(\mathbf{N}=\mathbf{1 0})$.

ulus, switching to the test stimulus simply continued the taste present.

\section{RESULTS}

Quality judgments and arlthmetic means of the magnitude estimates are shown in Figs. 1 through 4.

In each figure the adapting concentration in the magnitude estimate functions is indicated by the symbol used to designate points on the appropriate function, e.g., the $X$ indicates adaptation to water prior to each test stimulus. Each of the three boxes under quality judgments represents responses after one adapting solution. The adapting solution is indicated by an arrow. The top box, for example, shows taste qualities following adaptation to water. The results for $\mathrm{NaCl}$ (Fig. 1) are similar to those reported earlier (Bartoshuk et al, 1964; McBurney, 1966). The taste of the adapting solution completely disappeared during $40 \mathrm{sec}$, which is consistent with the complete adaptation found for taste by Abrahams et al (1937). A NaCl test stimulus

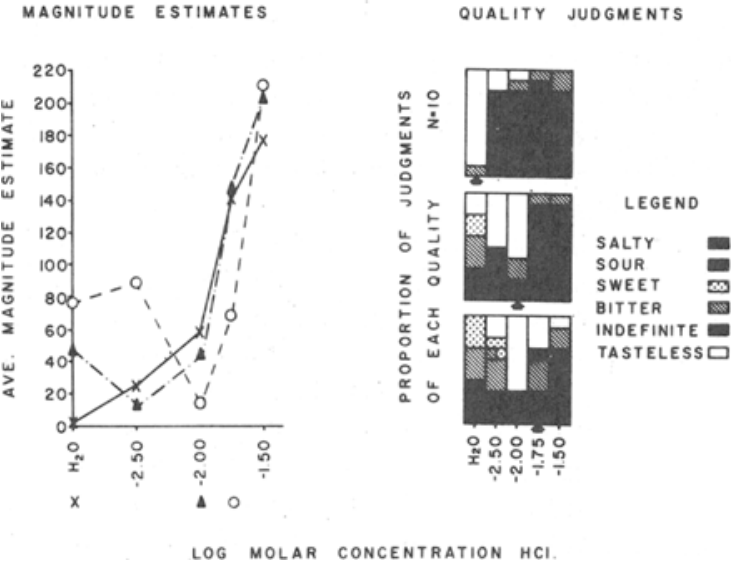

Fig. 4. Effects of adaptation to HCl on quality judgments and magnitude estimates of a concentration series of HCl solutions $(\mathbf{N}=\mathbf{1 0})$. 
of the same concentration as the adapting stimulus was called tasteless and given a magnitude of zero. Supra-adapting solutions had the typical salty taste found by Hahn (1934). However, sub-adapting solutions were not tasteless but on the contrary were reported as being bitter. The magnitude of the sub-adapting taste increased as the concentration decreased, with the maximum taste at water. The results for the other adapting solutions are similar but the sub-adapting qualities vary. The sub-adapting taste was sweet after adaptation to $\mathrm{QHCl}$ and bitter after adaptation to sucrose. Bartoshuk et al (1964) reported more sour sub-adapting tastes following adaptation to $\mathrm{NaCl}$ than were found in the present experiment. Their differing results could represent either individual differences in the quality of sub-adapting tastes or confusion in some Ss between sour and bitter tastes. The responses to water under the different adapting concentrations were tested for each of the four substances by a Friedman two-way analysis of variance. All adaptation effects were significant at the 0.05 level. The results for adaptation to $\mathrm{HCl}$ and $\mathrm{QHCl}$ require additional comment. For some Ss the $\mathrm{HCl}$ concentrations used became tasteless within $40 \mathrm{sec}$. For others, the taste did not completely disappear. For the latter $\mathrm{Ss}$, the test stimulus with the same concentration as the adapting solution was reported as having the typical taste of the adapting solution (sour for some Ss and bitter for others) rather than being tasteless (F1g. 4). However, these Ss noted that this taste was the same as that of the adapting solution. For the sub-adapting concentrations the tastes of the test solutions were reported to be distinct in either quality, magnitude or both from that of the adapting solution. If only responses different from the adapting solution had been plotted, the $\mathrm{HCl}$ functions would have reached zero at the adapting concentrations. With longer adaptation times the taste would probably have disappeared but additional exposure to HCl might have produced tongue damage. The subadapting qualities reported after adaptation to $\mathrm{HCl}$ show considerable variability. Most of the sophisticated Ss used in pllot work reported sweet sub-adapting tastes for $\mathrm{HCl}$. Some of the naive Ss in this experiment may have been distracted by the tactile component of $\mathrm{HCl}$ solutions or there may be individual differences in the sub-adapting taste qualities. One of the QHCl functions does not reach a minimum at the adaptation concentration for the same reason as the $\mathrm{HCl}$ curves did not as discussed above. This point also would be zero if only "different" judgments were included. In general, not all Ss reported all sub-adapting tastes but all Ss reported at least one.

The sub-adapting tastes reported did not depend on complete adaptation. The adapting stimulus was conthinued long enough for complete adaptation to occur for most Ss because the test stimulus then appeared as a taste after the tasteless adapting Bolution rather than as a new taste after the prior taste of the adapting solution. For naive Ss, the former type of judgment appeared to be easier.

These results confirm the observations in the last century that distilled water can have various tastes to man. These different tastes are contingent on the solution preceding the water. However, the effects are produced by all sub-adapting concentrations and not just water. Taste scales for the substances tested are thus sliding scales anchored to a zero point at the adapting concentration. When the concentration tasted is increased to supra-adapting values, the taste quality is that typically associated with the substance, e.g., sweet for sucrose, and increases in intensity with increasing concentration. When the concentration tasted is decreased to sub-adapting values, the taste quality is different from the quality typical of the substance and this new taste increases in intensity as the concentration tasted decreases. Thus the quality as well as the intensity of a taste solution depends on the concentration to which the tongue is adapted.

\section{DISCUSSION}

Early work on taste adaptation concentrated on the disappearance of sensation, the increase in absolute threshold and the time necessary for recovery (Abrahams et al, 1937; Krakhauer \& Dallenbach, 1937; Mayer, 1927; Hahn, 1934). These experiments emphasized only diminishing sensitivity as a result of continued stimulation and implied a loss of sensory information. In fact, "adaptation" has often been considered synonymous with "fatigue." More recently, Keidel et al (1961) have pointed out that the information capacity of a sensory modality can actually increase under conditions of constant stimulation. The present work provides an example of such increased capacity in taste. The adapting stimulus appears to modulate the meaning of subsequent input since the taste qualities of the sub-adapting stimuli change as a function of the adapting stimulus. These quality shifts increase the information available to the central nervous system. As additional effects of continued stimulation are studied, the term "adaptation" becomes harder to define. The different effects of constant stimulation probably do not all reflect a single underlying physiological process, "adaptation." For example, Bujas (1939) showed that increases in absolute threshold do not exactly parallel decreasing sensation intensity. Unfortunately, the single term adaptation has been used in different experimental contexts where different mechanisms are probably responsible for the effects observed and the conditions of constant stimulation seem to be the only commonallty. If "adaptation" is to be used to describe the modulation of sensory function by constant stimulation, it must at least be divested of the implication that sensitivity decrements or "fatigue" are necessarily involved. 
Since water is the solvent for almost all taste solutions, the sub-adapting tastes are important for the interpretation of other taste phenomena. In taste cross-adaptation experiments where the tongue is adapted to one substance and then tested with a second substance, decreased sensitivity to the second substance is interpreted as cross-adaptation. The present data indicate, however, that the second solution may produce a taste partly or completely due to the water solvent and not the solute. Some experimental results could, therefore, fail to show cross-adaptation even if it did occur. Supra-threshold interaction experiments which demonstrate the effects on some tastes of prior exposure to others could also lead to incorrect conclusions if sub-adapting tastes are overlooked. Some control observations can be made, however. A concentration series of the second substance can be tested. If the observed effect is due to the water solvent, the effect should increase as concentration decreases. If the effect is due to the solute, it should increase as concentration increases.

The mechanism producing sub-adapting tastes is still unknown; however, electrophysiological data in infra-human mammalian species suggests that the effect could be peripheral (Bartoshuk, 1965; Bartoshuk \& Pfaffmann, 1965). Four species (rat, hamster, cat and squirrel monkey) have been investigated electrophysiologically under stimulus conditions similar to those used with humans. Neural increments to water occurred in all four species but were contingent on the preceding "adapting" stimuli. These results differ from earlier reports which suggested that some species possess chorda tympani fibers responsive to water per se while others do not (Zotterman, 1956). The earlier reports were obtained, however, with only one adapting solution. The more recent electrophysiological results show in particular that the rat, previously classed with man as being without "water" fibers, shows chorda tympani increments to water under conditions of varying adapting solutions similar to those producing water and other sub-adapting tastes in man.

\section{Reterences}

Abrahams, H., Krakauer, D., \& Dallenbach, K. M. Gustatory adaptation to salt. Amer. J. Psychol., 1937, 49, 462-469.

Anderson, R. J. The taste of water. Amer. J. Psychol., 1959, 72, 462-463.

Bartoshuk, Linda M. Effects of adaptation on responses to water in cat and rat. (Doctoral dissertation, Brown University) Ann Arbor, Mich.: University Microfilms, 1965, No. 65-13, 630. Bartoshuk, Linda M., McBumey, D. H., \& Pfaffmann, C. Taste of sodium chloride solutions after adaptation to sodium chloride: implications for the "water taste". Science, 1964, 143, 967-968.
Bartoshuk, Linda M., \& Pfafmann, C. Effects of pre-treatment on the water taste response in cat and rat. Fed. Proc., 1965, 24, 207, Abstract no. 441.

Brown, W. The judgment of very weak sensory stimuli. $U$. of Calif. Publications in Psychol., 1914, 1, 1966-268.

Bujas, $Z$. Beobachtungen über den Restitutionsvorgang beim Geschmackssinn. Acta Inst. Psychol., Univ. Zagreb, 1939, 3, 3-14.

Camerer, W. Ueber die Abhangigkeit des Geschmackssinns von der gereizten Stelle der Mundhöhle. Z. Biol., 1870, 6, 440-452.

Hahn, H. Die Adaptation des Geschmackssinnes. Z. Sinnesphysiol. $1934,65,8-145$.

Haller, A. Von. First lines of physiology. Tr. from 3rd Latin ed., Primae lineae physiologiae; 1st ed., 1747. Philadelphia: Obadiah Penniman and Co., 1803.

Henle, J. Ueber den Geschmackssinn. Anthropologische Vorträge, $1880,2,1-24$

Kahlenberg, L. The action of solutions on the sense of taste. Bull. U. Wis. Sci. Series, 1898, 2, 1-31.

Keidel, W. D., Keidel, U. O., \& Wigand, M. E. Adaptation: loss or gain of sensory information? In W. A. Rosenblith (Ed.), Sensory communication. Cambridge, Mass.: M.I.T. Press, 1961.

Kiesow, F. Beiträge zur physiologischen Psychologie des Geschmackssinnes. Philosophische Studien, 1894, 10, 523-561.

Krakauer, D., \& Dallenbach, K. M. Gustatory adaptation to sweet, sour and bitter. Amer. J. Psychol., 1937, 49, 469-475.

Luciani, L. Human physiology. Tr. F. A. Welby. London: Macmillan and Co., 1917.

Mayer, B. Messende Untersuchungen über die Unstimmung des Geschmackswerkzeugs. Z. Sinnesphysiol., 1927, 58, 133-152.

McBumey, D. H. Magnitude estimation of the taste of sodium chloride after adaptation to sodium chloride. J. exp. Psychol., 1966, 72, 869-873.

Nagel, W. A. Über die Wirkung des Chlorsauren Kali auf den Geschmackssinn. Z, filr Psychol. und Physiol. den Sinnesorgane, $1896,10,235-239$.

Öhrwall, H. Untersuchungen uber den Geschmackssinn. Skand. Arch. Physiol., 1891, 2, 1-69.

Parker, G. H. Smell, taste and allied senses in the vertebrates. Philadelphia: J. B. Lippincott Co., 1922.

Richards, T. $W$. The relation of the taste of acids to their degree of dissociation. Amer. Chem. J., 1898, 20, 121-126.

Von Skramlik, E. Handbuch der Physiologie der Niederen Sinne. Leipzig: Georg Thieme, 1926.

Zotterman, $\mathbf{Y}$. Species differences in the water taste. Acta Physiol. Scand., 1956, 37, 60-70.

Zotterman, $\mathbf{Y}$, \& Diament, H. Has water a specific taste? Nature, $1959,183,191-192$.

\section{Noles}

1. The experiment on which this report is based was performed at Brown University while the author was a research associate with Dr. Carl Pfaffmann. The research was supported by grant GB-2754 from the National Science Foundation and was described at the April, 1966 meeting of the Eastern Psychological Association in New York.

2. The author expresses her gratitude to $R$. L. Burse for his most helpful suggestions on the manuscript.

(Accepted for publication September 13, 1967.) 